\title{
Blind Curves or Open Roads? Student Leaders Speak on the Future of Canadian Post-Secondary Education
}

\author{
Selena Demenoff, University of Northern British Columbia; Pascal Genest-Richard, \\ McGill University; Jolène Labbé, University of Guelph; Rébecca Bourgault, Champlain \\ College St-Lambert; Johanna Lewis, University of Toronto; Alannah Robinson, University \\ of Waterloo; John Pritz, McGill University; Cameron Bell, University of Northern British \\ Columbia; Laura Beach, Concordia University; Alexandre Beaupré-Lavallée, Université \\ de Montréal; Jessica Barudin, McGill University; Ray Charles Howard, Ryerson University; \\ Mimi Liu, University of Toronto; Sarah Nichols, Carleton University
}

In working to build a better, more just future, post-secondary institutions play a crucial role in shaping the students of today and tomorrow. Many institutions already employ a number of innovative programs aimed at broadening students' horizons. We can now look forward to seeing these initiatives grow. As students, we outline our views on some of the challenges and possible avenues for change in post-secondary education. Efforts to strengthen student leadership, optimize experiential learning, and develop a more holistic educational approach are important. Current challenges to post-secondary education lie within aspects of accessibility, funding, relationship disconnect, and segregated educational approaches. Strengths and challenges encountered within post-secondary education can frame learning boundaries to be deconstructive or constructive. Both boundary modalities can play important roles in designing the future of post-secondary education in Canada.

\section{Overview}

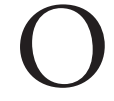
n July 22, 2012, we 14 students were invited to present the Closing Plenary at the 2012 Society for Teaching and Learning in Higher Education (STLHE) Conference. Comprised mainly of undergraduate students, including the inaugural cohort of $3 \mathrm{M}$ National Student Fellows, our group also included one CEGEP student and one graduate student. This article is a compilation of thoughts, perspectives, and experiences presented during the plenary. It is assumed that student ideas about the characteristics of effective higher education can provide essential guidance for (re)designing the future of postsecondary education (PSE). Author views and experiences vary; thus, statements herein may represent individual and/or collective perspectives. 


\section{Progressive Education Today}

What does progressive education look like at our institutions today? It seems traditional ways of evolving (that is, by somewhat rejecting the past ways of doing things and replacing them with opposing ones) are not limited to fine arts: they also apply to education, which can be considered an art in itself. As Plenary presenters, we unify adherence to this methodology when outlining what progressive education consists of. We emphasize the importance of: a) going beyond textbooks; b) allowing interdisciplinary approaches in order to bring precision to problems; c) associating scholarship with extracurricular involvements; d) encouraging freedom of social justice groups; and e) supporting research initiatives directly aimed at community applicability. We also value undergraduate research and process-based learning as opposed to traditional knowledgebased education, especially in non-professional programs. Some institutions already offer seminar courses for firstyear students, engaging them from the beginning of their academic journey and promoting self-guided learning. There are even cases of students creating the syllabus themselves: an innovative approach that has the potential to completely re-shape our vision of education.

\section{Progressive Education Tomorrow}

As post-secondary education is a cumulative experience, preparing for it is analogous to preparing for a journey. A quality education provides students with opportunities to apply their knowledge in the world beyond the classroom, giving them a sense of direction and community involvement. It is important to ensure that students are equipped to discuss and form opinions about relevant issues in their field, as what becomes common practice in universities and colleges often emerges as a template for social practice. Quality PSE teaches us to appreciate where we, as students, stand in relation to broader historical, political, cultural and economic trajectories. Postsecondary education provokes critical self-reflection about our beliefs, prejudices, motivations, choices and goals.

Post-secondary institutions (PSIs) have a role in catalyzing innovation and taking action on real-world problems. These institutions should encourage students to make meaningful contributions to their communities and provide them with resources and opportunities to prototype, implement, and evaluate their ideas. Post- secondary education should challenge students to embrace risk, and to learn from failure through facilitating the navigation of crises and ethical dilemmas.

Progressive education is best accomplished by supporting experiential learning (i.e., knowledge acquired through experience), which exemplifies higher education's philosophical and pedagogical needs and goals. Specifically, experiential learning demonstrates students' roles within the institution, within the community, and within themselves. Experiential learning enhances the way people relate. When we learn experientially, we engage our whole selves in the process as opposed to solely, for example, the 'analytical' part of ourselves. This approach allows students to engage trans-generationally, as well, with academic and non-academic citizens of the world. The dimensions of experiential learning amplify the voice of the youth, while underscoring and enforcing the value of practical initiatives.

\section{Designing the Future of Education: Building a Bridge Between Today and Tomorrow}

Any analysis of the post-secondary experience, purpose, and structure, must extend beyond the classroom. It is often perceived that the role of education within society is not debated enough, or at least not discussed enough in this time of economic and political questioning. Education is one of the most powerful tools we have to create social change, and it is thought that social change need never stop.

Financial barriers to PSE are unnecessary. Tuition could potentially be eliminated altogether through a progressive taxation system that adequately funds public sector education and through shifting governmental funding priorities towards long-term public good. Tuition is an issue that is as important as it is controversial, and should be recognized as such. In the province of Québec, a proposed tuition hike has recently been rejected. This increase in tuition fees was seen by some as a step towards an increased privatization of education, which may lead to greater inequality. 'Free' education comes with many challenges, however, which we can understand when analyzing some European and South American models that have embraced it (Morin, 2012). In these cases, barriers morph from financial to academic and a parallel private sector can emerge, leading to an unproductive two-speed system that fosters financial elitism. Many 
PSIs struggle to balance their budgets, partially due to insufficient government funding, and are increasingly filling this funding gap through corporate or private research investments and donations. Much governmentsponsored research is now tied to corporate or private research funding through 'matching funds' projects. David Bernans has argued that this funding paradigm gives corporations power to determine what gets taught in universities and what knowledge is sought. The Whirlpool Inc. Chairman, for example, has said, "We could not work with a university that has a long, drawn-out process for working with corporations. Rather, universities must listen to the needs of corporate customers and then quickly marshal the resources to solve the learning requirement" (Whitwam quoted in Meister, 1998, p. 188).

A dependency on corporate funding for the sustainability of institutions can also lead to disproportionate funding for 'profitable' departments - such as engineering and computer science - versus those traditionally viewed as less profitable areas of knowledge, including many of the social sciences and arts. This, in turn, de-emphasizes areas of knowledge transfer that are essential to the betterment of our society. Through attributing levels of hierarchy to different forms of education, education itself is weakened as a means for social betterment.

We must also examine and address the roots of how culture, colonialism, heritage, racism, classism, gender expectations, and other social forces all play into who can and cannot attend and succeed at PSIs. Let us remember that education is an important sphere of any society, and educated societies are often judged by their ability to facilitate equality, justice, and peace within learning. This funding gap can open the door for military funding and its influence on academia. It has been asserted that, "a university researching for the military, or for a military contractor, must reckon on the possibility that this research will help kill someone" (Dyer-Witheford, 2007, para. 6-9).

Transformational visions for the future of PSE require us to make connections to social issues. While fighting for accessible education, we must also fight for environmental justice, comprehensive healthcare, quality public childcare, sufficient cycling infrastructure, and for other crucial issues that are of local, provincial, national, and global relevance. We must recognize that we occupy many identities beyond that of student or of professor, and that universities are interconnected with society. At a systemic level, there needs to exist balance between research and teaching, especially in a paradigm where most of the endowment can be directed at research.

Post-secondary education should help prepare students to build meaningful lives as engaged and responsible citizens. The ideal learning environment is one where students are taught to view problems from multiple perspectives, rather than have disdain for thought processes different from their own. Post-secondary education should cultivate an ability to collaborate between different logics, paradigms, and world-views. If collaborations in learning saw no boundaries across disciplines, they would be empowered to fulfill their potential and find more effective and sustainable solutions to issues. This approach would challenge the elitist nature of academia that, some may argue, traditionally has thrived on segregation, competition, and one-way understanding.

The closer we come to individualized learning plans, the more students can get out of their education. Through this process, students will find themselves both educated and empowered. Within academia, we are also faced with the challenge of balancing passion and freedom. Teachers should be free to challenge their own expertise, especially if the aim is to stimulate creativity. Students should be given freedom with respect to the work they do and be allowed to step outside formal frameworks. Creativity, freedom of thought, and social service should be rewarded. After all, ideas that are as far removed from the existing ones end up being those we remember and leave a legacy for others.

Students can complete school with more than just grades, a degree, and stress management skills earned the hard way. A crucial component of holistic development is creating an environment conducive to good mental health. Many students experience anxiety, panic attacks, depression, suicidal thoughts, and other mental health issues. Struggles to deal with these issues are not a result of weakness, laziness, inadequate preparation, or poor timemanagement. Institutions need to ensure that students' experiences navigating mental health resources are not frustrating and alienating, but comfortable and enabling.

\section{Encouraging Student Leadership}

Students should not be told that they are 'leaders of tomorrow;' they should be told that they are the 'leaders of today' and be encouraged to solve current real-world problems. Students should have access to resources 
that enable them to dream, test, evolve, and challenge ideas. Students thirst for opportunities to experience the complexities of the real world, while becoming engaged in 'learning with consequences' that yields tangible outcomes.

Post-secondary institutions can foster cultures of collaboration and academic inclusion by recognizing that everyone has the potential to be an effective, impactful leader. By encouraging students to support and take pride in each other's growth, and by instilling a sense of individual and collective responsibility, student leadership can be optimized. Educators can ignite students' interests in the classroom, helping to combine personal passions with critical thought, leading to action and involvement on campus and in the community. Students value opportunities to reflect on their experiences, to gain a sense of self in relation to their environment, and to prepare for social, economic, and systemic challenges faced by our generation and beyond.

\section{Conclusion}

As student leaders from across Canada, we recognize that some challenges and opportunities in PSE are unique to each institution while others exist across the country. Structural and systemic changes are needed to address widespread issues such as funding, while individual institutions have the ability to target other needs such as opportunities for experiential education. Post-secondary institutions will continue to play an important role in shaping leaders and actively contributing to the betterment of society; their role is not to be taken lightly. As we ended the plenary with the following poem, we also felt it is fitting to do so here:

Far be it from me to say

What it is that students need

When at first they may endeavour

Not to follow but to lead

Perhaps they need a challenge

For failure strengthens resolve?

Perhaps they need support

To cushion them when they fall?

These questions I cannot answer

For no two of us are the same

But I think that to know this

Is to know our challenge by name
This much I feel for sure

Your encouragement cannot be hollow

For if it is felt and true

You will watch your students lead, where

others will only follow.

\section{Acknowledgments}

We are grateful to those who made the 3M NSF possible and contributed diligently in direct and indirect ways. These include the adjudicators and nominators, Arshad Ahmad, Mike Atkinson, Sylvia Avery, Don Cartwright, Alice Cassidy, Natalie Gerum, Valerie Lopes, Ron Marken, Ron Smith, Greg Snow, 3M Canada, Denise Stockley, and Angie Thompson. Thanks to those at the STLHE conference host institutions and organizing committee who worked to bring the student representatives on board: Janette Barrington, Dianne Bateman, Effi Kaoukis, Cynthia Weston, Laura Winer. We are grateful to the CELT organizers and anonymous reviewers. We offer special thanks to Alice Cassidy, 3M NSF Coordinator and facilitator extraordinaire, for organizational efforts in the months leading up to STLHE 2012 and for assisting us in preparation of this paper for publication.

\section{References}

Dyer-Witheford, N. (2007). Military Related Research at the University of Western Ontario. Science for Peace Bulletin, June 20.

Meister, J.C. (1998). Corporate Universities: Lessons in Building a World-Class Work Force. New York: McGraw-Hill.

Morin, J.Y. (2012). Une hausse qui freinera le développement du Québec. In L'éducation en péril: Pour mieux comprendre le printemps érable. Montréal: Fides.

\section{Biographies}

The 3M National Student Fellowship Award was introduced in 2012 to honour undergraduate students in Canada who have demonstrated qualities of outstanding leadership and who embrace a vision where the quality of 
their educational experience can be enhanced in academia and beyond. Read the full bios of this inaugural cohort at http://www.stlhe.ca/awards/3m-national-studentfellowships/2012-2/2012-3m-national-student-fellows/. For the plenary, $3 \mathrm{M}$ students were joined by CEGEP, undergraduate and a graduate student chosen by the institutions co-hosting the 2012 conference. 